\title{
A CASINHA DE VILANOVA ARTIGAS COMO SÍMBOLO DEMOCRÁTICO DO PATRIMÔNIO MODERNISTA PAULISTANO
}

\author{
A CASINHA BY VILANOVA ARTIGAS AS A DEMOCRATIC SYMBOL OF SÃO PAULO'S \\ MODERNIST HERITAGE
}

\section{Joäo Vicente Machado Schmitz}

Universidade Regional do Noroeste do Estado do Rio Grande do Sul, Ijuí, RS, Brasil. E-mail: joaoschmitz@outlook.com

\section{Maria Regina Johann}

Universidade Regional do Noroeste do Estado do Rio Grande do Sul, Ijuí, RS, Brasil. E-mail: maria.

johann@unijui.edu.br

Resumo: O artigo apresenta o diálogo entre arquitetura e sociedade a partir da obra a Casinha, um dos mais relevantes trabalhos de João Batista Vilanova Artigas, uma edificaçáo de renome dentro do cenário modernista da arquitetura paulistana. A proposição é apresentar o período de concepção da obra a partir da revolução técnico-construtiva da época, assim como questóes funcionais e plásticas. O Brasil vivera um período de resistência artística; 1922 trouxe inúmeras discussōes sobre a arte moderna que estava sendo importada e reformulada. Com isso, mesmo duas décadas mais tarde, o país se mostrava rígido arquitetonicamente, contando com poucas referências externas em pauta à arquitetura moderna - essa que, por sua vez, estava sendo estudada e difundida mundo afora. Em relação a metodologia, a presente investigaçáo versa sobre um estudo qualitativo, com base em referenciais bibliográficos e documentos audiovisuais. Em paralelo a trajetória do arquiteto, verifica-se que sua primeira residência não é somente uma mera obra de importância no cenário arquitetônico nacional, mas funcionou como um refúgio e espaço de deliberaçóes de Artigas, de seus amigos e alunos.

Palavras-chave: Função da Arquitetura. Democracia e Urbanidade. Arquitetura Modernista.

\begin{abstract}
The article presents the dialogue between architecture and society based on the work a Casinha, one of the most relevant works by Joáo Batista Vilanova Artigas, a renowned building within the modernist scenario of Sáo Paulo's architecture. The proposal is to present the period of conception of the work from the technical-constructive revolution of the time, as well as functional and plastic issues. Brazil had lived through a period of artistic resistance; 1922 brought numerous discussions about modern art being imported and reformulated. Even two decades later, the country was architecturally rigid, with few external references on the agenda to modern architecture - which, in turn, was being studied and


disseminated around the world. Regarding methodology, the present investigation is about a qualitative study, based on bibliographic references and audiovisual documents. The architect's first residence is not just a mere building of importance in the national architectural scenario, but it functioned as a refuge and space for deliberations by Artigas, his friends and students.

Keywords: Architecture function. Democracy and urbanity. Modern architecture.

\section{Introduçáo}

Toão Batista Vilanova Artigas nasceu em Curitiba (PR), no ano de 1915 e faleceu em 1985, aos 69 anos de idade, na cidade de Sáo Paulo. Forma-se engenheiro-arquiteto pela Escola Politécnica da Universidade de São Paulo (Poli-USP) em 1937 e, a partir de então, se configura em um dos nomes mais expressivos da arquitetura modernista brasileira, responsável por inúmeros projetos residenciais e importantes obras públicas (ITAÚ CULTURAL, 2018). Sua atuação profissional o fez ser conhecido como um homem ativo, energético, sempre pronto para superar os desafios da profissão e vivenciar suas ocupações como civil (KAMITA, 2000).

Inicialmente, suas obras são majoritariamente edificaçóes residenciais (aproximadamente duzentos exemplares), grande parte delas vinculadas à construtora Marone \& Artigas, que tinha como sócio o engenheiro Duílio Marone. Esse período de atuação profissional tem uma forte ênfase nas demandas da indústria civil, atendendo - em maior número -, a freguesia do ramo privado (KAMITA, 2000).

Segundo Cotrim (2005), no contexto urbano em que o trabalho de Artigas foi idealizado, a cidade de São Paulo se estabelece como um dos maiores pólos industriais no cenário brasileiro, mas é após a Primeira Guerra Mundial (1914-1918) que os Estados Unidos da América passa a ser uma referência importante, em aspectos que ultrapassam as questóes formais de arquitetura, especialmente a concepção estética de Frank Lloyd Wright se torna uma importante referência arquitetônica e social a Artigas.

Destarte, nesse primeiro momento de sua atuação, Artigas passa a reproduzir obras econômicas com pouco rebuscamento estilístico, que era consequência da grande demanda da construção civil. Contudo, por volta dos anos de 1940 - a partir do acesso a propostas modernistas por meio de revistas americanas que chegavam ao Brasil - vislumbra novas possibilidades plásticas e funcionais a implantar em seus projetos arquitetônicos (KAMITA, 2000), com especial interesse às obras de Frank Lloyd Wright. Influência essa que se amplia em 1946, quando Artigas tem a oportunidade de conhecer a arquitetura de Wright, ao passar uma temporada nos EUA momento em que foi contemplado com uma bolsa de estudos proporcionada pela Fundação Guggenheim; oportunidade que lhe abrem os horizontes em relação à arquitetura moderna americana.

Mediante tais consideraçóes é que se observa a relevância da construção da Casinha, que foi projetada com a peculiaridade de Artigas, com a qual buscou romper a estética da década de 1940, sendo uma experimentação audaciosa, tendo em vista o caráter paulistano daquela época. Por sua relevância estética e histórica, a obra foi tombada pelo Conselho de Defesa do Patrimônio Histórico, Arqueológico, Artístico e Turístico do Estado de São Paulo CONDEPHAAT (ESTADO DE SÃO PAULO, 2014) e, nisso se vislumbra a sua importância para a história da arquitetura modernista não exclusivamente de São Paulo, sobretudo do Brasil. 


\section{Metodologia}

O presente estudo manifesta-se a partir de uma abordagem qualitativa. Conforme aponta Cardano (2017), a tipologia investigativa supracitada é aquela que se dá pela construção e análise de dados característicos do objeto estudado. A pesquisa qualitativa permite uma autonomia do autor, influenciando a prática científica e metodológica a partir de publicações relevantes no cenário científico (POUPART et al., 2008).

Os estudos permearam publicaçôes, tais como artigos, livros e leis do Estado de São Paulo, a fim de reunir uma coletânea de informaçôes relevantes e pertinentes à pesquisa. Em sequência, foi feita uma análise de alguns documentários acerca da vida e obra de Artigas e demais contribuiçôes relevantes dentro do cenário social-arquitetônico.

\section{Breve trajetória política e social de Artigas}

Em 1944 Artigas se encontra engajado no cenário político e auxilia na fundação do Instituto de Arquitetos do Brasil, departamento de Sáo Paulo (IAB/SP), juntamente de outros colegas de profissão, buscando regulamentar e profissão (ITAÚ CULTURAL, 2018). De acordo com Kamita (2000), além de exercer seu cargo profissional em seu escritório com parceria de Marone, em 1945 João Batista filia-se ao Partido Comunista Brasileiro (PCB) iniciando - a partir de então - sua carreira também no horizonte da atuação política.

Se a arquitetura moderna aspira a uma real participação no processo de construção social da realidade, ela necessita comprometer-se com o real, assumir posiçốes, engajar-se em lutas, confrontar sistemas, enfim, assumir com consciência um sentido político (KAMITA, 2000, p. 9).

A passagem colocada pela autora supracitada reforça a ideia do pensamento de João frente ao seu posicionamento político-social, no qual ele primava a arquitetura como um corpo indissociável à política. A autora ilustra - por meio da tipografia - o paralelo entre a arquitetura moderna e a colocaçáo do ser em questão ao posicionamento frente ao novo movimento que se colocava à prática. Sadaike (2004) aponta que, no ano de 1948, de volta ao Brasil após um período no exterior, Artigas compóe o grupo de profissionais que vai se ocupar de planejar a proposta acadêmica e o projeto arquitetônico da Faculdade de Arquitetura e Urbanismo da Universidade de Sáo Paulo - FAU/USP, na qual inicia sua carreira como docente. Contudo, em 9 de abril de 1964, fora decretado o primeiro Ato Institucional (AI-1) como pretexto de resgatar a democracia, extinguir a corrupção e o comunismo no Brasil. A partir desse momento de tensôes políticas, as instituiçóes de ensino encontravam-se abaladas mediante o controle exercido pelo governo no cerceamento das liberdades individuais. Uma das instituiçóes mais afetadas nesse sentido foi a Universidade de São Paulo - USP, que era vista como uma das maiores universidades, com influência e com posturas rebeldes políticas, tendo seu reitor Gama e Silva reconhecido como um grande apoiador do golpe militar.

Mediante tal contexto, Gama e Silva afasta inúmeros pertencentes do corpo docente da USP, assim como funcionários e, também, alunos. Artigas foi um dos primeiros professores a ser retirado da Universidade. Em um primeiro momento, foi alegado que ele era o responsável por implementar, dentro do curso de Arquitetura, disciplinas de arte e estética (SADAIKE, 2004).

Acrescentando ao quadro, Sadaike (2004) coloca ainda que a militância assumida de 
João foi um dos aspectos facilitadores para que, posteriormente, ele ficasse preso por doze dias, sendo que em outubro de 1964, é indiciado e decide se exilar, juntamente de sua família, em Montevidéu, no Uruguai. Posteriormente, de forma clandestina, Artigas retorna ao Brasil no aguardo de seu habeas corpus, para que ele pudesse responder ao seu processo em liberdade. Nesse período, o PCB começa a ruir devido a divergências internas e Artigas mantém-se em hiato por um determinado tempo, tanto em sua atividade política, quanto profissional, no meio acadêmico e da construção civil.

Anos depois, em 1968, com o Ato Inconstitucional no 5, o terror político acentua-se e a USP, especificamente, passa a ser atingida novamente com mais pessoas sendo desligadas de seu corpo institucional. Em 1969 Artigas é aposentado da universidade e só retorna em 1979, no ano da anistia política, com um cargo que não correspondia ao de docente, exercido anteriormente. Em 1984 passa por novo concurso para ser professor titular na instituição; a qual o próprio fundara e projetara (SADAIKE, 2004).

Após 20 anos de violência, a ditadura militar aos poucos se esfacelou, mas, junto com ela, muitos brasileiros foram calados, torturados e mortos. Muitos não tiveram a oportunidade de presenciar a democracia brasileira sendo novamente estabelecida, como Vilanova Artigas, que faleceu no início de 1985 (SADAIKE, 2004, p. 264).

Depois de duas décadas do período da ditadura militar brasileira, a democracia ainda era colocada a prova. João vivera em um período de grande conflito sociopolítico e, mesmo assim, não deixara de exercer sua função enquanto pessoa física e profissional no que cerne a arquitetura; enquanto exilado no Uruguai, durante o período ditatorial, enviou uma carta aos formandos da FAU-USP -quando escolhido como paraninfo da turma-, apontando os inúmeros problemas do país daquele período (SADAIKE, 2004). Tendo em vista a repressão colocada àquela fase, inúmeras pessoas tiveram retirado o seu direito de fala e posicionamento. Portanto, é essencial elucidar o pensamento daqueles que foram restringidos aos atos democráticos, permitindo que suas vozes sejam ouvidas e, dessa forma, contribuindo à história do país.

\section{A Casinha: patrimônio histórico do modernismo brasileiro}

A Casinha foi construída no ano de 1942, ela surge pela fase wrightiana vivenciada por Artigas em meados da década de 1940 (KAMITA, 2000). Projetualmente, o engenheiroarquiteto rompe a estética e a forma de concepção das residências paulistanas do período; propóese uma implantação diferenciada, tratamento de fachada e disposição dos espaços internos, considerações expressas anteriormente nas obras de Wright (COTRIM, 2005).

Miura (2013) complementa o autor supradito, acrescentando que a residência localizavase distante do centro de Sáo Paulo, no bairro Campo Belo e a mesma havia sido projetada para que Artigas e sua companheira a desfrutassem aos finais de semana. $\mathrm{O}$ fato da edificaçáo ser distante do centro, contribuiu para que fosse possível romper paradigmas do racionalismo, libertando-se do padrão construtivo daquele tempo. A casa foi feita em planta irregular, tornando os ambientes únicos, com poucas divisôes verticais opacas, apresentando-se em diferentes níveis. Os materiais empregados na construção evidenciam a disposição de Artigas em inter-relacionar o tijolo aparente, a madeira e o vidro, oportunizando aos sujeitos que a plasticidade desses materiais servissem como elementos da experiência estética. 
A edificaçáo que viria a ser conhecida como a Casinha foi o primeiro objeto edificado projetado por Artigas à sua própria morada. O bem foi concebido em ângulo de $45^{\circ}$ no lote, contrariando qualquer hierarquia anteriormente seguida. Outro ponto destacado como fundamental à distribuição interna dos ambientes, foi a posição do banheiro e de uma lareira no centro do projeto, onde - a partir deles - os demais cômodos foram locados. Esse modelo de planta, a partir de um ponto central, associa-se com as obras de Frank Lloyd, que concebia a lareira como uma estrutura central e, por meio da qual, a casa era articulada a partir dos cômodos. Nesta perspectiva, Artigas propôs uma edícula, para fins funcionais, agrupada ao volume da casa, a sala integrada à cozinha, o dormitório e o estúdio integram-se no momento em que a ligação entre eles se dá por uma diferenciação de nível. Nessa concepção projetual, percebe-se a mínima utilização de paredes na divisão de ambientes, estratégia também praticada em projetos posteriores (COTRIM, 2005). Uma das importantes inovaçôes em termos de distribuição e organização dos ambientes internos diz respeito a ruptura que se faz em relação à tradição da arquitetura residencial brasileira, que mantinha uma hierarquia social a partir dos espaços: a cozinha e a área de serviços era apartada ou isolada dos demais ambientes de convívio familiar.

Frente à concepção projetual e histórica, a Casinha foi inscrita sob o no 428, p. 128, em 30 de dezembro de 2014, no livro do tombo histórico estadual, por meio do CONDEPHAAT, como um bem cultural, a fim de resguardar o bem tangível e sua ligação com a cidade de São Paulo, preservando a volumetria, fachada, a distribuição interna dos ambientes e volumes existentes, conforme o projeto original da obra. Assim, impossibilitando novas construçóes na área de preservação e, caso seja exigida alguma alteração, que sejam voltadas à manutenção e segurança, respeitando o bem protegido (ESTADO DE SÃO PAULO, 2014). A historiadora Rosa Artigas (fonte oral, 2015), filha do engenheiro-arquiteto, relata os inúmeros momentos que seu pai passava nessa residência junto de seus amigos políticos de esquerda, captando ondas curtas, para que fosse possível escutar as rádios europeias e, assim, lhes oportunizando que acompanhassem os acontecimentos relativos à $2^{\circ}$ Guerra Mundial; na expectativa de que o nazismo fosse combatido pelos aliados europeus. Dessa forma, destaca-se a importância dessa obra, no sentido de ter se tornado, além de um ícone modernista, também um espaço de mecanismo político durante muito tempo, sendo o berço de discussóes políticas de Artigas e seus colegas do $\mathrm{PCB}$, o que permite concluir que a residência se tornara uma sede informal do partido, a partir de posiçóes políticas de esquerda e a luta pela intelectualidade e democracia.

Por fim, ao se analisar a Casinha a partir do cenário político, a Revista Habitat (1950 apud ARTIGAS, 2015), publicou sobre os espaços existentes ali como aqueles que sáo abrigados contra as intempéries, mas não contra o ser humano; contraponto ao interno e externo, utilização do vidro em larga escala, pé-direito baixo, sendo a residência uma abertura ao social e político, um objeto construído que busca contrariar as barreiras impostas pela sociedade e pela construção civil à época em que fora construída.

\section{Consideraçóes finais}

Este estudo possibilitou compreender melhor a pessoa de João Batista Vilanova Artigas e a sua relevância à arquitetura modernista brasileira, na medida em que dá visibilidade para a amplitude de seus projetos. Em síntese, constata-se o homem politizado, o arquiteto sensível às causas sociais de uma sociedade em transformação. 
Inspirando-se em grandes mestres como Wright e Le Corbusier, Artigas soube traduzir ideias e concepçôes modernas à luz da sociedade brasileira. Contemporâneo aos ideais sociais de sua época, materializa nas suas edificaçôes, tanto residenciais quanto públicas, valores de democracia, convívio social e abertura à modernidade por meio das estruturas e dos materiais. Artigas inova e sua estética dá visibilidade à materialidade do concreto aparente, aos vãos amplos e iluminados e a ambientes integrados e integradores.

Sua sensibilidade à arte, o leva a participar de ateliers artísticos nos fazendo crer que havia nele uma predisposição a aprender e a inter-relacionar as linguagens artísticas à arquitetura. São exemplos disso, a Residência de Olga Baeta (1956) e de Rubem de Mendonça (1958), a conhecida Casa dos triângulos.

Contudo, é necessário mencionar que a Casinha é sua obra singular. Ela é a expressão da ruptura estética das tendências Neoclássica e Art Déco, que predominavam na paulicéia desvairada, como assim se referiu Mário de Andrade a São Paulo.

Mais do que um refúgio, a Casinha é uma obra que rompe com valores arraigados na sociedade brasileira, traduzidos nas residências que segregam as pessoas por sua função ou status social: o quartinho da empregada, a cozinha distante da sala, o setor de serviços como um espaço desprovido de conforto e acolhimento, que ilustrava, por meio da arquitetura, os resquícios da Casa grande e da senzala (FREYRE, 1992). Ao integrar os ambientes, nos parece que Artigas envia um recado à sociedade brasileira: a modernidade passa por aspectos sociais, e enquanto o Brasil não romper com a discrepância social e seguir discriminando as pessoas por sua condição étnica e social, nós estaremos distante dos ideais promulgados no final do Século XIX e pelos quais muitas pessoas pagaram com suas vidas, inclusive nos Séculos vindouros.

O que nos ensina a concepção da Casinha de Artigas? Entre tantas coisas, a de que a arquitetura diz de nós e, portanto, é uma expressão das relações históricas, dos valores de uma sociedade e da visão que se tem de homem e meio. Nisso, Artigas deixou um inspirador legado.

Ressalta-se, ainda, a importância de reconhecer um bem patrimonial e toda sua potencialidade histórica, para que essas relevantes informaçôes e sua identidade sigam sendo repassados às geraçôes seguintes, a partir da consciência e educação patrimonial, que contribuem para a vida em sociedade.

\section{Referências}

ARTIGAS, Rosa. Uma morada de Artigas. Ou das vicissitudes dos proprietários de imóvel tombado na cidade de São Paulo e alguns apelos. Minha Cidade, São Paulo, ano 15, n. 176.02, mar. 2015. Disponível em: https://www.vitruvius.com.br/revistas/read/ minhacidade/15.176/5453. Acesso em: 02 ago. 2020.

CASINHA (1942): centro de irradiação política - Ocupação Vilanova Artigas. Direção: Laura Artigas e Pedro Gorski. Produção: Olé Produções. Produção executiva: Gal Buitoni e Luiz Ferraz. Som: Diego da Costa; Luís Rovai; Rene Brasil e Tomás Franco. Diretor de fotografia: Zé Mario Fontoura. São Paulo, SP: Itaú Cultural, 2015. Disponível em: https://www.youtube. com/watch?v=IZWaRvfmxbc. Acesso em: 26 jul. 2020.

CARDANO, Mario. Manual de pesquisa qualitativa. Petrópolis, RJ: Vozes, 2017. 
COTRIM, Marcio. A casinha de Artigas: reflexos e transitoriedade. Arquitextos, São Paulo, ano 06, n. 061.01, jun. 2005. Disponível em: https://www.vitruvius.com.br/revistas/read/ arquitextos/06.061/449. Acesso em: 02 ago. 2020.

FREYRE, Gilberto. Casa-grande \& Senzala. 28. ed. Rio de Janeiro: Record, 1992.

ITAÚ CULTURAL de Arte e Cultura Brasileiras. Vilanova Artigas. São Paulo: Itaú Cultural, 2018. Disponível em: http://enciclopedia.itaucultural.org.br/pessoa13159/vilanova-artigas. Acesso em: 02 de ago. 2020. Verbete da Enciclopédia.

KAMITA, João Masao. Vilanova Artigas. São Paulo: Cosac \& Naify, 2000.

MIURA, Priscila Miyuki. O reconhecimento das obras de Artigas pelo CONDEPHAAT. In: SEMINÁRIO DOCOMOMO BRASIL, 10., out. 2013, Curitiba. Disponível em: https:// docomomo.org.br/wp-content/uploads/2016/08/OBR_67.pdf. Acesso em: 29 jul. 2020.

POUPART, J. A pesquisa qualitativa: enfoques epistemológicos e metodológicos. Petrópolis, RJ: Vozes, 2008.

SADAIKE, Patrícia.1964: os impactos do golpe militar na carreira acadêmica e artística do arquiteto Vilanova Artigas. Projeto História, São Paulo, v. 29, p. 257-266, dez. 2004. Disponível em: https://revistas.pucsp.br/revph/article/view/9957. Acesso em: 31 jul. 2020.

Sáo Paulo (Estado). Decreto-lei no 149, de 15 de agosto de 1969. Dispóe sobre o tombamento de bens, para a proteção do patrimônio histórico e artístico estadual. Diário Oficial do Estado de São Paulo. 31 dez. 2014; Seção 1.

Vilanova Artigas: o arquiteto e a luz. Dirigido por Laura Artigas; Pedro Gorski, 2015. 